\title{
Impact of human pressure and forest fragmentation on the Endangered Barbary macaque Macaca sylvanus in the Middle Atlas of Morocco
}

\author{
Nelly Ménard, Yann Rantier, Adrien Foulquier, Mohamed Qarro \\ Lahcen Chillasse, Dominique Vallet, Jean-Sébastien Pierre and Alain Butet
}

\begin{abstract}
Overexploitation of forests by humans can lead to highly fragmented populations of forest-dependent species that have poor dispersal abilities. We tested the influence of habitat quality, landscape structure and human pressure on densities of the Barbary macaque Macaca sylvanus in the largest wild population, in the Middle Atlas of Morocco. We surveyed 14 forest fragments of $5-142 \mathrm{~km}^{2}$ that are separated from each other by an inhospitable matrix. We estimated the habitat quality of these forest patches by analysing the vegetation structure and the intensity of human pressure. We studied the distribution of forest patches and estimated macaque densities by combining line-transect sampling and complete group counts. We estimated mean density of individuals to be $9 \mathrm{~km}^{-2}$ (range $0.2-23 \mathrm{~km}^{-2}$ ). Differentiation of forest patches by a principal component analysis did not show any significant relationship between vegetation type and macaque density. A linear regression model showed that human pressure had a negative impact on density and that density responded positively to patch size. Patch shape, connectivity and altitude did not explain variation in population density. The size of this population is estimated to be c. 5,000 individuals. The survival of several small subpopulations is seriously threatened. As the Middle Atlas is the stronghold of this Endangered species, we recommend modifying forestry practices, reducing overgrazing by livestock within forests, and halting clear-cutting of holm oaks.
\end{abstract}

Keywords Forest fragmentation, habitat quality, landscape structure, Middle Atlas, population density, primate, specialist species, threatened species

Nelly MÉnard (Corresponding author) and Dominique Vallet UMR 6553, ECOBIO: Ecosystems, Biodiversity, Evolution, CNRS/University of Rennes 1, Biological Station of Paimpont, 35380 Paimpont, France. E-mail nelly.menard@ univ-rennes1.fr

Yann Rantier, Jean-Sébastien Pierre, Alain Butet UMR 6553, ECOBIO: Ecosystems, Biodiversity, Evolution, CNRS/University of Rennes 1, Rennes, France

ADRIEN FoulquiER Veterinary School, Toulouse, France

Mohamed QARro National School of Engineers in Forestry, Salé, Rabat, Morocco

LAHCen ChILLASSE University of Moulay Ismail, Meknes, Morocco

Received 15 January 2012. Revision requested 10 February 2012.

Accepted 23 February 2012. First published online 26 July 2013.
This paper contains supplementary material that can be found online at http://journals.cambridge.org

\section{Introduction}

T abitat fragmentation and loss, and degradation of 1 habitat quality from human activities are among the main threats to wildlife populations (Wilcox \& Murphy, 1985; Andren, 1994; Fahrig, 2003; Mortelliti et al., 2010a). Fragmentation processes can also lead to population extinction in small areas (Debinski \& Holt, 2000; Fischer \& Lindenmayer, 2007), and recolonization processes become critical for specialist species that use a limited number of habitat types in the landscape (Franken \& Hik, 2004).

Large and long-lived mammals are generally recognized to be highly sensitive to human pressures and habitat change. Studies on large mammals are mostly limited to solitary species (Mortelliti et al., 2010b) and only rarely focus on species living in social groups (Graham et al., 2009; Hewison et al., 2001). Social organization (group size, degree of philopatry of females, sex-biased dispersal, spatio-temporal stability of home ranges) is an important determinant of the ability of a social species to survive in a disturbed landscape and to colonize habitat fragments. In particular, habitat specialists and highly social species living in large groups are among the most negatively affected by habitat fragmentation and degradation (Swihart et al., 2003). Sociality and sex-biased dispersal may impose limits on colonization rates or on the size of a patch that can support a viable population because social groups are key parameters to population growth. It is still unknown to what extent patch quality and landscape structure (patch size, patch shape, isolation) affect the persistence of large forestdependent mammals living in social groups.

To address these questions, we studied a forestdependent and long-lived social species, the Barbary macaque Macaca sylvanus. This species lives in large multi male-multi female social groups of 10-88 individuals (Ménard \& Vallet, 1993a). Females are philopatric, living all their life in their natal group, whereas the males disperse. The wild Barbary macaque's distribution is limited to scattered and isolated forest fragments in Algeria and 


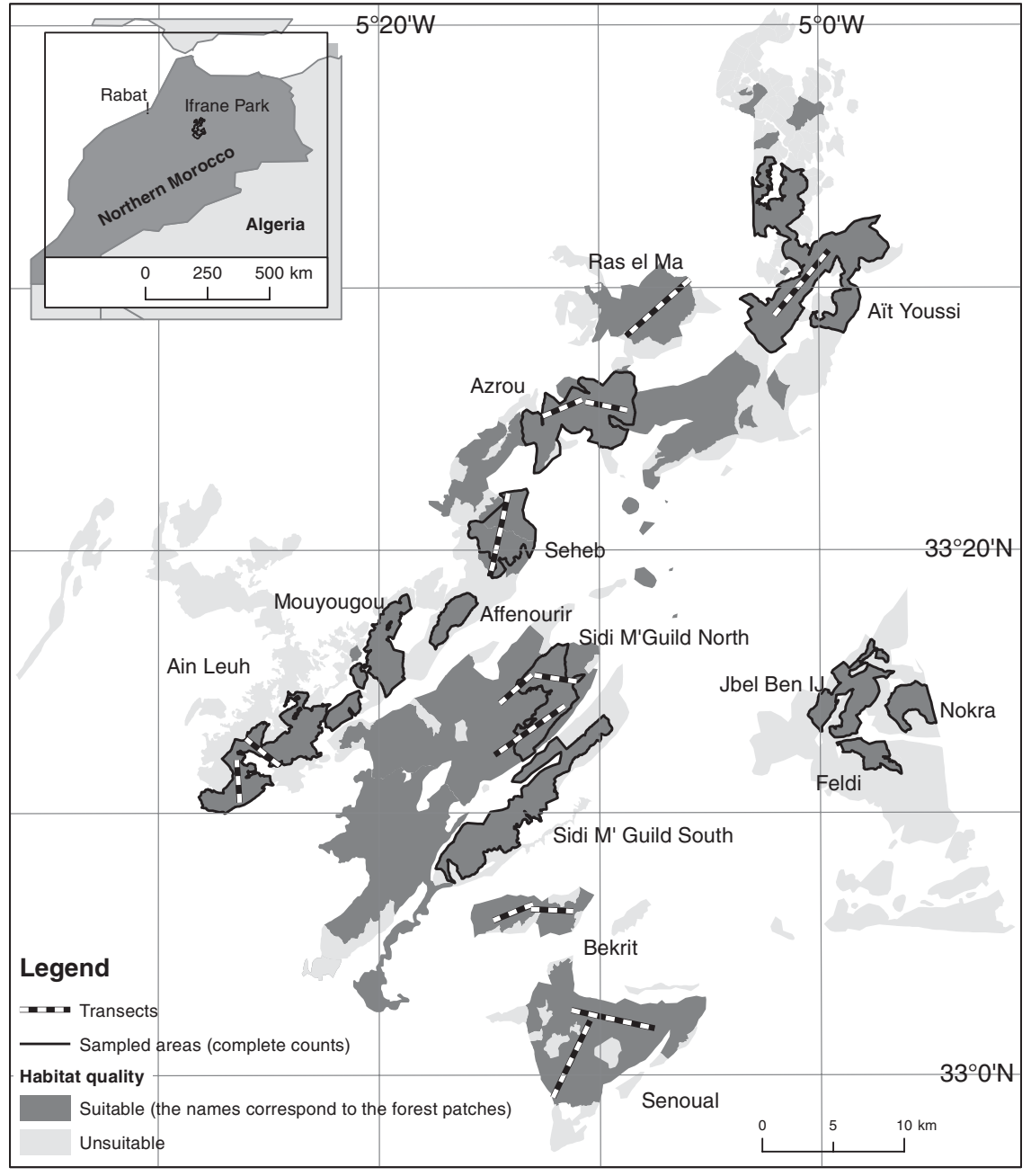

FIG. 1 The study area, showing the 14 forest patches potentially suitable for the Barbary macaque Macaca sylvanus, and unsuitable forest patches, and the locations where we surveyed for the macaque using line transects and complete counts. White shading indicates cultivated areas and villages. The areas where we carried out complete counts at Sidi M'Guild North, Azrou and Seheb were 17.1, 29.11 and $15.21 \mathrm{~km}^{2}$, respectively. The shaded area on the inset (Ifrane National Park) indicates the location of the main map in the Middle Atlas of Morocco.
Morocco, most of them containing $<500$ individuals. The largest population is in the Middle Atlas of Morocco, assumed to contain c. $75 \%$ of the north African population (c. 15,000 individuals; Taub, 1977; Fa, 1984). Decline of Barbary macaques in the Middle Atlas during the last 20 years has been attributed to the loss of cedar forests (Camperio Ciani et al., 2005) and the taking of young Barbary macaques for the pet trade (van Lavieren, 2008; van Lavieren \& Wich, 2009). The remaining forest fragments of the Middle Atlas suffer from heavy human pressure, overgrazing by sheep and goats, and cedar pruning during shortages of food for livestock (Lamb et al., 1991). Barbary macaques forage $>50 \%$ of their time on herbaceous and shrub plants (Ménard \& Vallet, 1996). Therefore, domestic livestock are strong competitors. The Barbary macaque is categorized as Endangered on the Red List of Threatened Species (Butynski et al., 2008) and is listed in Appendix II of CITES (CITES, 2013).

Our study aimed to provide up-to-date information on the distribution and abundance of the Barbary macaque in the Middle Atlas of Morocco. We compared the influence of landscape structure (patch area and shape, and patch connectivity), and habitat composition and quality, on macaque density. We considered the intensity of forest use by humans for livestock as an index of habitat quality, and also potential effects of altitude, which could interact with human pressure in montane regions.

\section{Study area}

The study area comprised $985 \mathrm{~km}^{2}$, mainly in the Ifrane National Park (Middle Atlas, Fig. 1), and included all areas subject to management by foresters. The Middle Atlas forest is mainly composed of mixed evergreen cedar-oak forests (Cedrus atlantica and Quercus rotundifolia). The study area is divided into numbered parcels by foresters, who carry out a regular silvicultural management programme consisting of cedar logging and the clear-cutting of holm oaks. 


\section{Methods}

\section{Characterization of habitat types and degree of habitat fragmentation}

We drew up a vegetation map from Sogreah-Ttoba (2004), which was updated with recent vegetation changes. We then classified each vegetation parcel as suitable or unsuitable for Barbary macaques, based on knowledge of their ecology (Fig. 1). Each Barbary macaque group uses a relatively stable home range. Barbary macaques need tall mature trees to avoid predators, either for nocturnal sleeping sites or to escape from danger during their daytime foraging activities. Consequently, open grasslands, immature oak coppices, degraded forest with heavily pruned or scattered cedars, and agricultural areas constitute an inhospitable matrix that macaque groups have never been observed to cross (Taub, 1977; Ménard \& Vallet, 1996, 1997).

A total of 14 forest fragments whose size exceeded the home range $\left(3-4 \mathrm{~km}^{2}\right)$ of Barbary macaque groups (Ménard \& Vallet, 1996) were retained as sampling plots (Fig. 1). We described each forest patch using seven habitat descriptors: vegetation community, index of human pressure, mean altitude, area, shape, and two measures of patch connectivity (Kindlmann \& Burel, 2008; Prugh, 2009), here referred to as distance and connectivity. The index of human pressure was based on estimations of the intensity of overgrazing by sheep and goats and the intensity of cedar pruning in each forest patch (Sogreah-Ttoba, 2004; see Supplementary Table $S_{1}$ for calculations). Shape index was calculated using Eq. (1), where $p_{i}$ is the perimeter of the patch $i$ and $a_{i}$ is its area (McGarigal et al., 2002).

$$
\text { Shape }=\frac{p_{i}}{2 \sqrt{\pi^{*} a_{i}}}
$$

Distance, Eq. (2), is the minimum distance to the nearest occupied patch, where $h_{i j}$ is the nearest edge-to-edge distance between the focal forest patch and its neighbouring forest patch.

$$
\text { Distance }=h_{i j} k
$$

Connectivity is a distance-weighted area of the occupied patch, using Eq. (3), where $d_{i j}$ is the distance $(\mathrm{km})$ between focal patch $i$ and patch $j, A_{j}$ is the area $\left(\mathrm{km}^{2}\right)$ of the forest patch $j$, and $\alpha$ is $1 / d r l$. As social groups are units of colonization in this species (see Discussion), $d r l$ is the maximum observed day range length for a Barbary macaque group $(3.00 \mathrm{~km}$; Ménard \& Vallet, 1997), which allows a group to cross the matrix from one sleeping site to another within 1 day.

$$
\text { Connectivity }=\sum_{j \neq i} \exp \left(-\alpha d_{i j}\right) A_{j} k
$$

\section{Census methods}

Censuses were conducted in the 14 forest fragments. Variables related to censuses were spatially referenced using ArcView v. 9.2 (ESRI, Redlands, USA). When possible we preferred to use complete counts to estimate densities but this method requires intense sampling that was impracticable over large areas (Fashing \& Cords, 2000; Marshall et al., 2008). Consequently, we used the linetransect method in several patches. At least 40 observations are needed to estimate densities from line-transect surveys (Marshall et al., 2008) and we therefore applied a correction factor to density estimates obtained in forest patches where line transects alone were used, after determining the relationship between densities derived from complete counts and line transects in forest patches where both methods were used. We used both methods in five forest patches, only line transects in three patches and only complete counts in six patches (Fig. 1).

Censuses using line transects were carried out in October 2007 and 2008. October is the most suitable month for such surveys because the diurnal activity of the macaque is relatively stable at this time (Ménard \& Vallet, 1997), thus avoiding sampling biases from variations in the probability of detection. We sampled 10 line transects in eight forest patches comprising $526 \mathrm{~km}^{2}$ (Fig. 1). Each transect was $6 \mathrm{~km}$ (four comprised two lines of $3 \mathrm{~km}$ ) and was repeated at least four times, except for one that was repeated three times. The total distance surveyed was $234 \mathrm{~km}$. The beginning and direction of the lines were chosen to ensure that the surveys were entirely within forest patches.

There were four survey teams, each of two people. Censuses started at 06.00. Speed along transects was a maximum of $1 \mathrm{~km} \mathrm{~h}^{-1}$. At each sighting of macaques the observers noted the date, hour, location (with a global positioning system), and distance and angle to the first macaque sighted. The first sighted macaque was assumed to be located at the edge of the group. As groups have a greater chance of being detected than individuals (Buckland et al., 2010), macaque groups were considered the sample units. The centres of detected groups were subsequently located on the map based on the estimated spread of the group (c. $100 \mathrm{~m}$ for a group of 15-25 individuals and c. $150 \mathrm{~m}$ for a group of 25-40; authors, unpubl. data) and the perpendicular distances from each group centre to transect line were estimated using ArcView.

Complete counts were carried out in 11 forest patches between March 2007 and October 2008, in sampled areas in three sites and over the whole of eight sites (Fig. 1). Observers made accurate counts of entire groups as they crossed a road or a track. The description of several individuals in each group allowed its identification.

\section{Estimation of densities}

Perpendicular modelling of group centres uses a detection function of perpendicular distances from a group centre to the transect line. We used DISTANCE 6 release 2 
(Thomas et al., 2010) to fit a set of detection probability models to the observed perpendicular distances. We selected the best model according to the smallest value of Akaike's information criterion corrected for small samples (AICc; Burnham \& Anderson, 2002). In this manner, DISTANCE estimates the proportion of groups missed by the survey and computes the population density and size in the survey area. A mean group size in each forest zone sampled was implemented as a parameter for density estimation with DISTANCE (Table 1).

\section{Influence of the environment on density}

We examined the influence of four descriptors of the vegetation community (\% cedar, cedar-oak or pine forest, $\%$ mature oak forest, $\%$ oak coppice, $\%$ open grassland or shrubby formation) on the density of individuals and groups of macaques. Data analysis was in two stages. Firstly, we computed a principal component analysis (PCA) of the environmental descriptors (four variables, 11 forest patches); three of the 14 patches were excluded because they were pooled for density estimation (see Results). Data were arcsin-transformed before analysis. We then carried out a regression of macaque abundance against the first two axes of the PCA. All analyses were carried out with $R$ (R Development Core Team, 2010).

A multiple linear regression (function $l m$ in $R$ ) was used to examine the effect of six environmental variables (human pressure, altitude, area, shape, distance and connectivity; Supplementary Table S1) on macaque density. Model selection procedure was based on AICc. The model with the lowest AICc was chosen as the best fitting and the most parsimonious. Models with $\triangle \mathrm{AICc}<2$ from the best model were considered equally effective for explaining variations in density. For each model we calculated AIC weight $\left(w_{i}\right)$, which gives the relative importance of each variable in explaining variations in density. These calculations were made using the MuMIn package in $R$.

\section{Results}

\section{Vegetation types and forest patches}

The study area is a complex vegetation mosaic. Pure and mixed mature forests cover c. $58 \%$ of the study area, oak coppices $22 \%$, and open grasslands and scattered shrubby formations $20 \%$. A total of $539.2 \mathrm{~km}^{2}$ was judged suitable for macaques $(54 \%$, Fig. 1). The inhospitable matrix (agricultural areas excluded) was mainly composed of open vegetation, grasslands or shrubby formations $(26 \%)$, low and scarce oak coppices (36\%) and sparse and pruned cedars $(28 \%)$. Each forest patch was composed of a mosaic of vegetation formations (Supplementary Table S2). Eleven forest patches were mainly mixed cedar-oak formations $(>50 \%)$ and two patches were mostly pure oak formations. Each forest patch contained $2-23 \%$ open grassland or shrubby formations scattered in small areas. The area of forest patches was 5-142 $\mathrm{km}^{2}$.

\section{Macaque density}

Estimated macaque densities were 0-23.4 individuals per $\mathrm{km}^{2}$ and $0-0.7$ groups per $\mathrm{km}^{2}$ (Table 1, Supplementary Fig. S1). Seven forest patches each contained $<100$ individuals. We detected 40 groups with line transect surveys. Calculations in DISTANCE showed that the uniform+cosine model had the lowest AICc value. The half strip width within which macaque groups had the highest probability (100\%) of being detected was $161.9 \mathrm{~m}$. This value exceeded the distance at which macaques were detected (mean $39 \mathrm{~m}$; range 10-70 $\mathrm{m}$ ) because group centres were used in analyses rather than the position of the first macaque sighted. The results obtained from complete counts and line transect surveys varied comparably between sites. However, densities were overestimated by line transects, by a factor of 1.4-1.8, compared to densities obtained from complete counts at the same sites (Table 1). We used densities from line transects, divided by a correction factor of 1.6, to estimate densities at the three sites (Ras El Ma, Bekrit, Senoual) where we only surveyed with line transects (Table 1). The total number of macaques in the sampled area was estimated to be 4,972. The mean density among the sampled forest patches was 9.2 individuals per $\mathrm{km}^{2}$.

\section{Influence of environmental variables on density}

The PCA of the four vegetation descriptors clearly separated the 11 forest patches (data not presented). Axis 1 accounted for $65.6 \%$ of the variation in the data and distinguished forest patches dominated mostly by oak formations (mature oak forests or oak coppices; e.g. Aïn Leuh) from those occupied by mixed cedar-oak or pine forest (e.g. Nokra, Seheb), and Axis 2 for $21.8 \%$, grouping patches according to the percentage cover of open areas such as grasslands, shrubby formations and oak coppices (e.g. Azrou, Jbel Ben IJ). Macaque density did not have any relationship with the PCA coordinates of forest patches, indicating that the abundance of macaques was not sensitive to the characteristics of forest patch vegetation (Fig. 2).

Multiple linear regressions with six environmental variables as predictors of macaque density, in 11 forest patches, indicated that human pressure was the best predictor (Table 2). The second most supported model $(\triangle \mathrm{AICc}<2)$ included only area (Table 2). The sum of all Akaike weights containing human pressure indicated that it was the most 
TABLE 1 Densities $\left(D_{\mathrm{s}}\right.$, number of groups $\mathrm{km}^{-2} ; D$, number of individuals $\left.\mathrm{km}^{-2}\right)$, encounter rates of groups $(n / L ; n$, number of observations of groups; $L$, total survey effort in km), and abundance of the Barbary macaque Macaca sylvanus in the 14 forest patches (the data for the patches Bekrit, Ras el Ma and Senoual were pooled) surveyed in the Middle Atlas (Fig. 1), estimated from complete counts and line-transect surveys.

\begin{tabular}{|c|c|c|c|c|c|c|c|c|}
\hline \multirow[b]{2}{*}{ Forest patch } & \multicolumn{3}{|c|}{ Complete counts } & \multicolumn{5}{|l|}{ Line transects } \\
\hline & $D_{\mathrm{s}}$ & $D$ & $\begin{array}{l}\text { No. of groups/ } \\
\text { individuals }\end{array}$ & $n / L(95 \% \mathrm{CI})$ & $D_{\mathrm{s}}(95 \% \mathrm{CI})$ & $D^{1}(95 \% \mathrm{CI})$ & $\begin{array}{l}\text { No. of individuals } \\
(95 \% \mathrm{CI})\end{array}$ & $\% \mathrm{CV}^{2}$ \\
\hline Azrou $^{3}$ & 0.41 & 7.1 & $34 / 591$ & $0.21(0.16-0.39)$ & $0.64(0.34-1.20)$ & $10.9(5.8-20.5)$ & $911(485-1,710)$ & 20 \\
\hline Sidi M'Guild North ${ }^{3}$ & 0.7 & 23.4 & $100 / 3,329$ & $0.33(0.24-0.46)$ & $1.09(0.75-1.41)$ & $32.9(24.0-45.1)$ & $4,685(3,419-6,421)$ & 13 \\
\hline Bekrit, ${ }^{4}$ Ras el Ma, ${ }^{4}$ Senoual ${ }^{4}$ & $0.23^{5}$ & $5.2^{5}$ & $543^{5}$ & $0.12(0.07-0.21)$ & $0.37(0.22-0.64)$ & $8.3(4.9-14.3)$ & $872(510-1,491)$ & 25 \\
\hline Aït Youssi ${ }^{3}$ & 0.04 & 0.5 & $2 /$ c. $25^{6}$ & $0^{7}$ & & & & \\
\hline Aï Leuh ${ }^{3}$ & 0.07 & 0.2 & $2 /$ c. $30^{6}$ & $0^{7}$ & & & & \\
\hline Jbel Ben IJ ${ }^{8}$ & 0.13 & 2 & $2 /$ c. $30^{6}$ & & & & & \\
\hline Feldi $^{8}$ & 0.2 & 4 & $1 /$ c. $20^{6}$ & & & & & \\
\hline Mouyougou $^{8}$ & 0.23 & 8.2 & $3 /$ c. $105^{6}$ & & & & & \\
\hline Affenourir ${ }^{8}$ & 0.36 & 12 & $2 /$ c. $70^{6}$ & & & & & \\
\hline Total & 0.33 & 9.2 & 4,972 & $0.17(0.12-0.23)$ & $0.74(0.61-0.91)$ & $19.6(15.7-24.6)$ & $6,864(5,483-8,592)$ & 10 \\
\hline
\end{tabular}

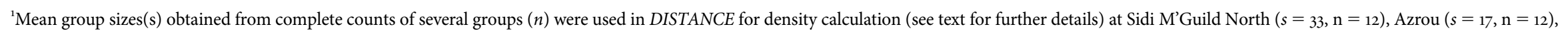
Seheb $(s=20, \mathrm{n}=8)$, Bekrit $(s=27, \mathrm{n}=11)$, Senoual $(s=23, \mathrm{n}=3)$ and Ras el Ma $(s=17, \mathrm{n}=3)$.

${ }^{2}$ Coefficient of variation of density

${ }^{3}$ Both line transects and complete counts were conducted. Within the areas sampled in Azrou, Seheb and Sidi M'Guild North (Fig. 1) densities $\left(D_{\mathrm{s}}\right.$ and $\left.D\right)$ were estimated from complete counts, including 207 individuals (twelve groups), 171 individuals (eight groups) and 400 individuals (12 groups), respectively.

${ }^{4}$ Only line transects were used. The three sites (Bekrit, Ras el Ma, Senoual) where few macaque groups were detected during line transects were grouped for density analysis using DISTANCE.

${ }^{5}$ Densities obtained by line transects for the three pooled patches were corrected by dividing by 1.6, and the new values were considered reliable estimates of those that would have been obtained by complete counts (see text for further details)

${ }^{6} \mathrm{We}$ did not obtain exact group sizes because groups did not cross paths.

${ }^{7}$ The sites where no macaques were detected during transects were excluded from analyses with DISTANCE.

${ }^{8}$ Only complete counts were conducted. 

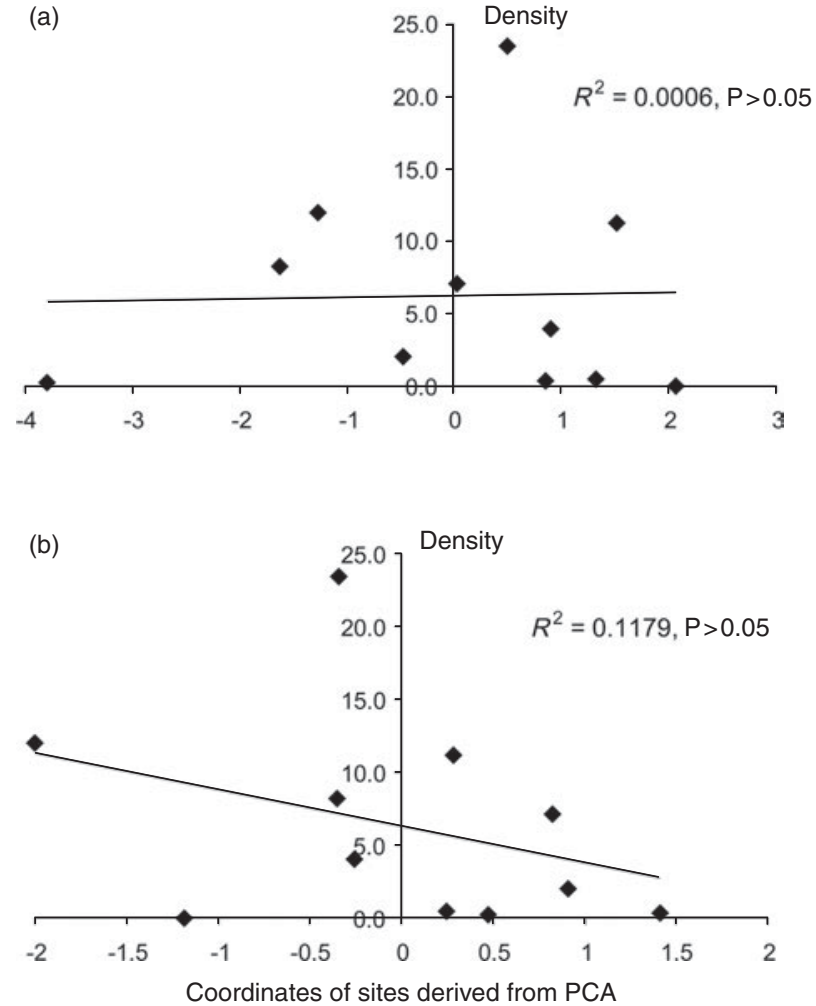

FIG. 2 Linear regression between macaque density and (a) Axis 1 (PC1) and (b) Axis 2 ( $\mathrm{PC}_{2}$ ) of a principal component analysis (PCA) of the vegetation descriptors of the 11 forest patches (Table 1).

important variable. Densities significantly decreased as human pressure increased $\left(F_{1,9}=8.39, \quad \mathrm{P}=0.018\right.$, $\left.R_{\mathrm{adj}}^{2}=0.43\right)$ and increased when patch area increased $\left(F_{1,9}=5.85, \mathrm{P}=0.038, R_{\mathrm{adj}}^{2}=0.33\right.$, Fig. $\left.3 \mathrm{a}, \mathrm{b}\right)$. However, when we excluded the largest patch the correlation between density and patch size was not significant $\left(F_{1,8}=0.06\right.$, $\left.\mathrm{P}=0.812, R_{\mathrm{adj}}^{2}=0.11\right)$. We found no relation between density and the shape or degree of connectivity of forest patches, or their altitude $\left(F_{1,9}<1, \mathrm{P}>0.1\right)$.

\section{Discussion}

The forested areas in the study site in the Middle Atlas of Morocco are partly transformed into oak coppices, a result of clear-cutting of holm oaks. Open areas of oak coppices are unsuitable habitats for macaques, whereas pure mature oak forests may harbour at least $20 \mathrm{~km}^{-2}(\mathrm{Fa}, 1984)$. With recent climate change, which has led to a decrease in winter snow, some shepherds stay in the high mountains during the winter, and during food shortages they prune cedars to feed their livestock (Lamb et al., 1991). These practices, combined with overgrazing by sheep and goats, have led to a gradual disappearance of forests, soil erosion, and loss of diversity and abundance of herbaceous and shrub resources in comparison with preserved cedar-oak forests (Ménard \&
Qarro, 1999). The consequence of habitat loss and degradation of forest areas is fragmentation of habitat suitable for macaques into forest patches of varying size.

Comparisons with previous censuses at two sites in the Central Region of the Middle Atlas (Azrou: 10 individuals $\mathrm{km}^{-2}$; Ain Kahla, i.e. Sidi M'Guild North forest: 36-44 individuals $\mathrm{km}^{-2}$; Taub, 1977; $\left.\mathrm{Fa}, 1984\right)$ vs 7.1 and 23 individuals $\mathrm{km}^{-2}$ in our study show a decrease in density of c. $40 \%$ in 30 years. This is in agreement with a study carried out in 2005 in the same two forests (van Lavieren \& Wich, 2009). However, van Lavieren \& Wich (2009) observed smaller mean group sizes (6-9) compared with those that we found with our complete counts (17-33), and higher mean group density $\left(2.1-3.3 \mathrm{~km}^{-2}\right.$ vs $\left.0.6-1.1 \mathrm{~km}^{-2}\right)$, which suggests they observed several parties of groups that they considered to be different groups, perhaps because they were spread in the forest. Our estimate of a total population of c. 5,000 Barbary macaques in the Middle Atlas is about three times less than that estimated 30 years ago (c. 15,000; Taub, 1977). The decline is probably a result of the decrease in macaque density in areas of suitable habitat and the disappearance of entire forest fragments. We found that macaque densities varied greatly between forest patches $\left(0-23 \mathrm{~km}^{-2}\right)$. A high intensity of human pressure and/or small patch size appear to be responsible for the low macaque densities. However, the lack of relationship between density and patch size when the largest patch of $140 \mathrm{~km}^{2}$ was removed from the analysis suggests that a possible area threshold exists between this largest patch and the second largest of $\mathrm{c} .80 \mathrm{~km}^{2}$, below which the size effect disappears. Macaques may depend more on the quality of herb and shrub layers, related to the intensity of livestock grazing, than on forest structure. We did not find evidence of an effect of patch connectivity, which suggests a lack of functional connectivity between patches and that patches may be too far apart for macaques to move between them.

The study of behavioural ecology has facilitated the understanding of the effects of changes in landscape structure on the abilities of populations to persist in or recolonize an area (Lima \& Zollner, 1996; Lawes et al., 2000; Kie et al., 2005). Social organization can also limit the resilience of a species to the effects of habitat loss, degradation and fragmentation but, to our knowledge, few studies have taken into account the influence of sociality (Lawes et al., 2000; Swihart et al., 2003; Graham et al., 2009). We hypothesize that specialist habitat-dependent species of large mammal living in large social groups in which only one sex disperses will be particularly vulnerable to habitat fragmentation and loss because sociality may restrict colonization. Migrating male Barbary macaques alone cannot successfully colonize or recolonize an area: only social groups can do so. Group fission is the only way for females to disperse but, as observed in similar forests in Algeria, this leads to the formation of new groups that 
TABLE 2 Model selection of predictors of macaque density based on Akaike's information criterion corrected for small sample size (AICc), and relative importance of predictor variables assessed by summing the AIC weights $\left(w_{i}\right)$ from each model containing that predictor.

\begin{tabular}{|c|c|c|c|c|}
\hline Models $^{1}$ & $\mathrm{AICc}$ & $\Delta \mathrm{AICc}^{2}$ & $w_{i}$ & Importance \\
\hline Human pressure & 75.86 & 0.00 & 0.46 & 0.73 \\
\hline Area & 77.60 & 1.74 & 0.19 & 0.33 \\
\hline Human pressure + area & 78.80 & 2.94 & 0.11 & \\
\hline Human pressure + altitude & 79.61 & 3.75 & 0.07 & \\
\hline Human pressure + distance & 80.66 & 4.80 & 0.04 & \\
\hline Human pressure + shape & 81.03 & 5.17 & 0.03 & \\
\hline Shape & 82.27 & 6.41 & 0.02 & \\
\hline Connectivity & 82.60 & 6.74 & 0.02 & \\
\hline Area + altitude & 82.77 & 6.91 & 0.01 & \\
\hline Altitude & 82.82 & 6.96 & 0.01 & \\
\hline Distance & 83.05 & 7.19 & 0.01 & \\
\hline Human pressure + area + altitude & 83.75 & 7.89 & 0.01 & \\
\hline Human pressure + distance + area & 84.96 & 9.10 & 0.00 & \\
\hline Human pressure + distance + altitude & 86.22 & 10.36 & 0.00 & \\
\hline Human pressure + shape + altitude & 86.47 & 10.61 & 0.00 & \\
\hline Shape + altitude & 87.47 & 11.61 & 0.00 & \\
\hline Connectivity + altitude & 87.84 & 11.98 & 0.00 & \\
\hline Distance + altitude & 88.02 & 12.16 & 0.00 & \\
\hline Human pressure + distance + area + altitude & 92.58 & 16.72 & 0.00 & \\
\hline
\end{tabular}

${ }^{1}$ Patch shape, connectivity and area were not tested together because the calculation of each of them included a measure of area and they were therefore considered to be strongly correlated with each other. Distance and connectivity were not tested together because the calculation of each of them included a measure of distance. Human pressure and connectivity were not tested together because they were significantly negatively correlated $\left(F_{1,9}=13.03, \mathrm{P}=0.005\right.$, $\left.R_{\mathrm{adj}}^{2}=0.55\right)$. The other predictors were independent $(\mathrm{P}>0.05)$. Shapiro-Wilk normality test on the models did not show any departure from normality $(\mathrm{P}>0.1)$.

${ }^{2}$ Models with $\triangle \mathrm{AICc}<2$ are considered equally plausible in explaining variations in density.
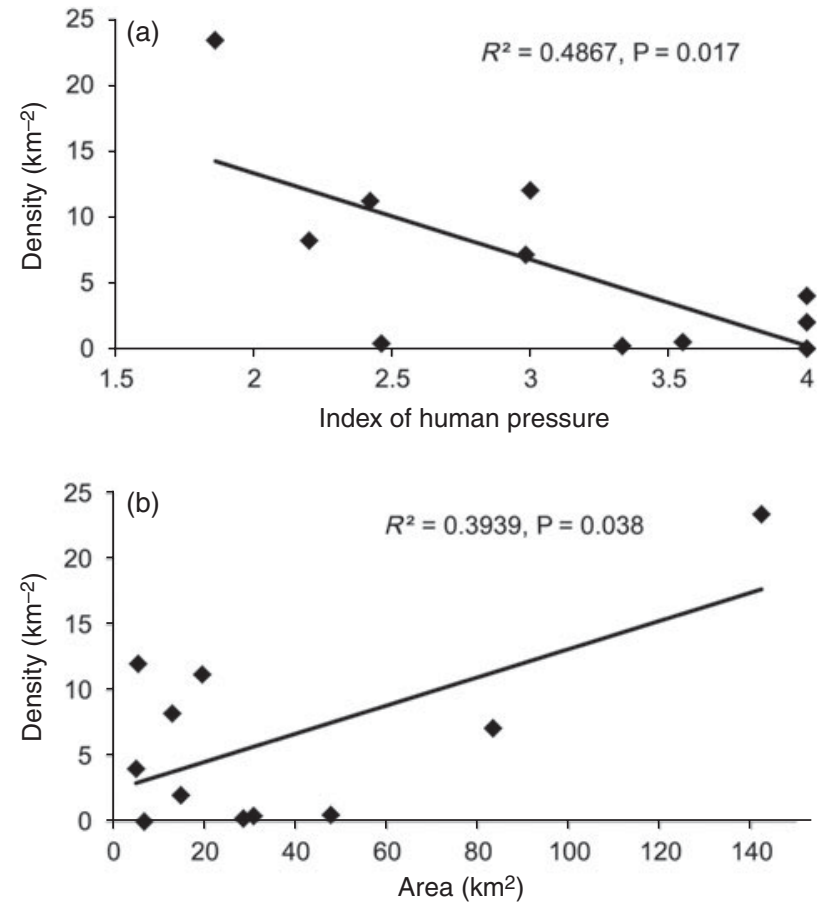

FIG. 3 Linear regressions between macaque density and (a) an index of human pressure and (b) area of the 11 forest patches (Table 1). remain in the same forest patch (Ménard \& Vallet, 1993b). Barbary macaques are able to move outside the forest to feed in adjacent open grasslands or oak coppices (Ménard \& Vallet, 1997). However, studies of the home range use by several focal groups have not observed macaques crossing wide open areas or moving more than c. $200 \mathrm{~m}$ from the forest edge (Taub, 1977; Ménard \& Vallet, 1996). We believe that the social organization of Barbary macaques, with the total philopatry of females and their strong, stable residence in their home ranges, high sociality and large cohesive groups, reliance on mature forests, and requirement for groups of trees for an entire group to sleep or to escape from danger, limits the likelihood of movement between patches. This probably explains why this macaque is sensitive to the quality and size of forest patches whereas density does not seem to be influenced by the structure of the landscape. These traits appear to predispose the species to local extinction because fragmented populations are likely to be entirely isolated.

In the near future we suspect that stochastic events will extirpate the Barbary macaque in forest patches where their density is close to zero (Melbourne \& Hastings, 2008; Traill et al., 2010). These patches will not be recolonized, even if suitable, because of the low dispersal abilities of this macaque and the reduced connectivity of the landscape. Forest patches are separated by areas that were formerly 
wooded but are now degraded. Approximately $64 \mathrm{~km}^{2}(14 \%)$ of these areas could be restored in the medium term, the time necessary for oak coppices to reach maturity. Such restoration could create corridors between six of the 14 actual forest patches, which would reduce the number of patches to nine (N. Ménard, unpubl. data). In addition, expanded forest patches could exceed the area threshold to become more favourable for the conservation of the macaque. In contrast, c. $23 \mathrm{~km}^{2}$ within four of the existing forest patches are heavily degraded and becoming more unsuitable for the macaque as a result of cedar pruning. We estimate that the outcome of this process will fragment these patches, increasing the number of forest patches from 14 to 18 (N. Ménard, unpubl. data). If human pressures persist the population of Barbary macaques in the Middle Atlas will be in danger of extinction. In addition, it has been predicted that with climate change $C$. atlantica will disappear from the Middle Atlas but will persist in the south-west High Atlas (Cheddadi et al., 2009). Consequently, we recommend the development of mature holm oak forests instead of using clear-cutting management techniques, and favour the expansion of new forests at higher altitudes. The Middle Atlas will otherwise become dominated by mobile and generalist species (Devictor et al., 2008).

In conclusion the population of the Barbary macaque in the Middle Atlas continues to decline, and locally low densities result from habitat loss, unsuitable forestry practices and competition with livestock. We therefore recommend halting the clear-cutting of holm oaks and restriction of the number of sheep and goats within the forest. Poaching of young macaques for illegal trade is an additional threat to this already declining population (van Lavieren, 2008; van Lavieren \& Wich, 2009), leading to a deficit of immature individuals.

\section{Acknowledgements}

Financial support for this study came from the contract Service Provincial des Eaux et Forêts d'Ifrane/University of Rennes 1, with N. Ménard and M. Qarro as the French and Moroccan scientific leaders, respectively. We thank all the team of the Ifrane National Park project, Z. Amhaouch, I. Bouziane, B. Elasri, N. Elrouat, L. Oukannou and Mr. A. Sayad (Association of the Friends of the National Park of Ifrane), who participated in the line-transect sampling in 2007 and 2008. This study was conducted in close partnership with the Haut Commissariat aux Eaux et Forêts et à la Lutte contre la Désertification and the Regional Director of Eaux et Forêts du Moyen Atlas at Meknes. We thank P. Le Gouar for helpful comments, J. Nabucet for help with geographical information system analysis, F. Cuzin for information on Barbary macaque groups on Jbel Ben IJ, and two anonymous reviewers for helpful comments. We are grateful to Helen Whitfield for revising the language of this article. This is a scientific production of UMR CNRS 6553, Caren-OSUR, University of Rennes 1.

\section{References}

Andren, H. (1994) Effects of habitat fragmentation on birds and mammals in landscapes with different proportions of suitable habitat: a review. Oikos, 71, 355-366.

Buckland, S.T., Plumptre, A.J., Thomas, L. \& Rexstad, E.A. (2010) Design and analysis of line transect surveys for primates. International Journal of Primatology, 31, 833-847.

Burnham, K.P. \& Anderson, D.R. (2002) Model Selection and Multimodel Inference: A Practical Information-Theoretic Approach. Springer, New York, USA.

Butynski, T.M., Cortes, J., Waters, S., Fa, J., Hobbelink, M.E., VAN LAVIEREN, E. et al. (2008) Macaca sylvanus. In IUCN Red List of Threatened Species v. 2012.2. Http://www.iucnredlist.org [accessed 14 February 2013].

Camperio Ciani, A.C., Palentini, L., Arahou, M., Martinoli, L., Capiluppi, C. \& Mouna, M. (2005) Population decline of Macaca sylvanus in the Middle Atlas of Morocco. Biological Conservation, 121, 635-641.

Cheddadi, R., Fady, B., Francois, L., Hajar, L., Suc, J.P., Huang, K. et al. (2009) Putative glacial refugia of Cedrus atlantica deduced from Quaternary pollen records and modern genetic diversity. Journal of Biogeography, 36, 1361-1371.

CITES (2013) Species Database Report. Http://www.unep-wcmc.org/ cites-species-database_50o.html/ [accessed 15 February 2013].

Debinski, D.M. \& Holt, R.D. (2000) A survey and overview of habitat fragmentation experiments. Conservation Biology, 14, 342-355.

Devictor, V., Julliard, R. \& Jiguet, F. (2008) Distribution of specialist and generalist species along spatial gradients of habitat disturbance and fragmentation. Oikos, 117, 507-514.

FA, J.E. (1984) Habitat distribution and habitat preference in Barbary macaques (Macaca sylvanus). International Journal of Primatology, 5, 273-286.

FAHRIG, L. (2003) Effects of habitat fragmentation on biodiversity. Annual Review of Ecology, Evolution, and Systematics, 34, 487-515.

FAshing, P.J. \& Cords, M. (2000) Diurnal primate densities and biomass in the Kakamega Forest: an evaluation of census methods and a comparison with other forests. American Journal of Primatology, 50, 139-152.

Fischer, J. \& Lindenmayer, D.B. (2007) Landscape modification and habitat fragmentation: a synthesis. Global Ecology and Biogeography, $16,265-280$.

Franken, R.J. \& Hik, D.S. (2004) Influence of habitat quality, patch size and connectivity on colonization and extinction dynamics of collared pikas Ochotona collaris. Journal of Animal Ecology, 73, 889-896.

Graham, M.D., Douglas-Hamilton, I., Adams, W.M. \& Lee, P.C. (2009) The movement of African elephants in a human-dominated land-use mosaic. Animal Conservation, 12, 445-455.

Hewison, A.J.M., Vincent, J.P., Joachim, J., Angibault, J.M., Cargnelutti, B. \& Cibien, C. (2001) The effects of woodland fragmentation and human activity on roe deer distribution in agricultural landscapes. Canadian Journal of Zoology-Revue Canadienne de Zoologie, 79, 679-689.

Kie, J.G., Ager, A.A. \& Bowyer, R.T. (2005) Landscape-level movements of North American elk (Cervus elaphus): effects of 
habitat patch structure and topography. Landscape Ecology, 20, 289-300.

Kindlmann, P. \& Burel, F. (2008) Connectivity measures: a review. Landscape Ecology, 23, 879-890.

Lamb, H.F., Damblon, F. \& Maxted, R.W. (1991) Human impact on the vegetation of the Middle Atlas, Morocco, during the last 5,000 years. Journal of Biogeography, 18, 519-532.

Lawes, M.J., Mealin, P.E. \& Piper, S.E. (2000) Patch occupancy and potential metapopulation dynamics of three forest mammals in fragmented Afromontane forest in South Africa. Conservation Biology, 14, 1088-1098.

Lima, S.L. \& Zollner, P.A. (1996) Towards a behavioral ecology of ecological landscapes. Trends in Ecology and Evolution, 11, 131-135.

Marshall, A.R., Lovett, J.C. \& White, P.C.L. (2008) Selection of line-transect methods for estimating the density of group-living animals: lessons from the primates. American Journal of Primatology, 70, 452-462.

McGarigal, K., Cushman, S.A., Neel, M.C. \& Ene, E. (2002) FRAGSTATS v3: Spatial Pattern Analysis Program for Categorical Maps. Computer software program produced by the authors at the University of Massachusetts, Amherst, USA. Http://www.umass. edu/landeco/research/fragstats/fragstats.html [accessed 20 June 2013].

Melbourne, B.A. \& Hastings, A. (2008) Extinction risk depends strongly on factors contributing to stochasticity. Nature, 454, 100-103.

Ménard, N., Foulquier, A., Vallet, D., Qarro, M., Le Gouar, P. \& Pierre, J.-S. (2013) How tourism and pastoralism influence population demographic changes in a threatened large mammal species. Animal Conservation, doi: 10.1111/acv.12063.

Ménard, N. \& Qarro, M. (1999) Bark stripping and water availability: a comparative study between Moroccan and Algerian Barbary macaques (Macaca sylvanus). Revue d'Ecologie-La Terre et La Vie, 54, 123-132.

Ménard, N. \& Vallet, D. (1993a) Population dynamics of Macaca sylvanus in Algeria: an 8-year study. American Journal of Primatology, 30, 101-118.

Ménard, N. \& Vallet, D. (1993b) Dynamics of fission in a wild Barbary macaque group (Macaca sylvanus). International Journal of Primatology, 14, 479-500.

Ménard, N. \& Vallet, D. (1996) Demography and ecology of Barbary macaques (Macaca sylvanus) in two different habitats. In Evolution and Ecology of Macaque Societies (eds J.E. Fa \& D.G. Lindburg), pp. 106-145. Cambridge University Press, Cambridge, UK.

Ménard, N. \& Vallet, D. (1997) Behavioral responses of Barbary macaques (Macaca sylvanus) to variations in environmental conditions in Algeria. American Journal of Primatology, 43, 285-304.

Mortelliti, A., Amori, G. \& Boit Ani, L. (2010a) The role of habitat quality in fragmented landscapes: a conceptual overview and prospectus for future research. Oecologia, 163, 535-547.
Mortelliti, A., Amori, G., Capizzi, D., Rondinini, C. \& BoITANi, L. (2010b) Experimental design and taxonomic scope of fragmentation studies on European mammals: current status and future priorities. Mammal Review, 40, 125-154.

PRUGH, L.R. (2009) An evaluation of patch connectivity measures. Ecological Applications, 19, 1300-1310.

R Development Core Team (2010) A Language and Environment for Statistical Computing. R Foundation for statistical computing, Vienna, Austria. Http://www.r-project.org/ [accessed 5 July 2011].

Sogreah - Ttoba (2004) Etudes d'aménagement concerté des forêts et des parcours collectifs de la Province d'Ifrane. Carte d'occupation des sols et description parcellaire. Service Provincial des Eaux et Forêts d'Ifrane, Meknès, Morocco.

Swihart, R.K., Gehring, T.M., Kolozsvary, M.B. \& Nupp, T.E. (2003) Responses of 'resistant' vertebrates to habitat loss and fragmentation: the importance of niche breadth and range boundaries. Diversity and Distributions, 9, 1-18.

TAUB, D.M. (1977) Geographic distribution and habitat diversity of the Barbary macaque Macaca sylvanus L. Folia Primatologica, 27, 108-133.

Thomas, L., Buckland, S.T., Rexstad, E.A., Laake, J.L., Strindierg, S., Hedley, S.L. et al. (2010) Distance software: design and analysis of distance sampling surveys for estimating population size. Journal of Applied Ecology, 47, 5-14.

Traill, L.W., Brook, B.W., Frankham, R.R. \& Bradshaw, C.J.A. (2010) Pragmatic population viability targets in a rapidly changing world. Biological Conservation, 143, 28-34.

van Lavieren, E. (2008) The illegal trade in Barbary macaques from Morocco and its impact on the wild population. Traffic Bulletin, 21, 81-88.

van Lavieren, E. \& Wich, S.A. (2009) Decline of the Endangered Barbary macaque Macaca sylvanus in the cedar forest of the Middle Atlas Mountains, Morocco. Oryx, 44, 133-138.

Wilcox, B.A. \& MurPhy, D.D. (1985) Conservation strategy: the effects of fragmentation on extinction. American Naturalist, 125, $879-887$.

\section{Biographical sketches}

Nelly Ménard and Dominique Vallet have been studying the ecology and demography of the Barbary macaque since 1982 . Y ANN RANTIER is a specialist in geographical information systems. ADRIEN Foulquier is a veterinarian. MOHAMED QARRo has been studying pastoralism in the Middle Atlas for many years. LAHCEN CHILLASSE is developing research on the ecology of birds and mammals in Morocco. Jean-Sébastien Pierre specializes in population dynamics, modelling and statistics. A LA IN BUTET focuses on research in landscape ecology. 